\title{
Dental fear: a narrative review
}

\author{
Nowrin J. Nishi ${ }^{1 *}$, Shahana Pervin ${ }^{1}$, Syed Shaude ${ }^{2}$
}

${ }^{1}$ Dhaka Dental College and Hospital, Dhaka, Bangladesh

${ }^{2}$ International Online Journal Hub, Dhaka, Bangladesh

Received: 01 February 2022

Revised: 18 February 2022

Accepted: 19 February 2022

\author{
*Correspondence: \\ Dr. Nowrin J. Nishi, \\ E-mail: nowrinjahannishi5@gmail.com
}

Copyright: (C) the author(s), publisher and licensee Medip Academy. This is an open-access article distributed under the terms of the Creative Commons Attribution Non-Commercial License, which permits unrestricted non-commercial use, distribution, and reproduction in any medium, provided the original work is properly cited.

\begin{abstract}
The dental fear and anxiety (DFA) is a common phenomenon around the world. From children to the adults, most of the people become frightened when they face any dental discomfort and they need to visit a dentist and go through a treatment procedure in a dental set up. This narrative review tends to identify the causes behind DFA, its consequences and management of DFA from different studies which were conducted previously. This study is a narrative review of DFA. This study is mainly based on the secondary data from different articles and journals which were available online. After the proper screening from 154 titles, the final review included 68 articles. Based on different studies, it is found that DFA in quiet common in the people of all ages. The studies had found that dental fear and anxiety most often results from a traumatic past dental experience. Friendly dental office environment is an effective way in reducing dental fear and anxiety. Psychotherapeutic management is also important is managing DFA like behavior-management techniques, relaxation techniques, distraction, guided imagery, hypnotherapy, acupuncture, systematic desensitization or exposure therapy, positive reinforcement, cognitive restructuring and pharmacological management. The techniques for managing DFA can be the effective solution for reducing stress and make the treatment process more comfortable.
\end{abstract}

Keywords: Dental fear, Dental anxiety, Etiology, Consequences, Managing DFA

\section{INTRODUCTION}

Dental fear is basically an emotional reaction or emotional outburst when a person faces dental diseases and he/she has to visit a dentist for dental treatment. ${ }^{1}$ According to Moore dental fear consist of fear of dental procedures, fear dental environment or clinical settings, fear of dental instruments and even fear of the dentist as a person. ${ }^{2}$ Dental fear sometimes result in patients delaying or avoiding dental treatment in due time. ${ }^{1}$ This delay and avoiding of visiting the dentist and avoiding dental treatment may causes more further dental and oral complication as well. The term dental anxiety refers to a state of suspicion and apprehension especially thinking that, something very wrong or bad is going to happen in relation to the treatment, and it is generally coupled with a sense of losing control. ${ }^{1}$ These two terms 'dental fear' and 'dental anxiety' are frequently used alternatively, so the common term 'dental fear and anxiety' (DFA) is used in this writing. Another term 'dental phobia' is special type of fear, because of proportion to the demands of the situation. Dental phobia can't be reasoned logically and sometimes becomes beyond control and results to the avoidance of dental treatment although this is really unavoidable. $^{3}$ However, dental phobia sometimes is considered to be a separate concept. The diagnosis of dental phobia is a bit complicated as it cannot be analyzed purely from the presence of dental fear or anxiety and for this the patient's history of dental experiences must be taken into consideration as well. ${ }^{4}$ The patient who experiences a high level of dental fear or anxiety together with a history of avoiding a visit to the dentist totally, we can diagnose it as dental phobia because from the previous discussion we learned that a phobic person has a tendency 
to completely avoid of the perceived danger. This distinction must be made because it is far more easy to manage a patient with dental fear and anxiety than a patient who has dental phobia. ${ }^{4}$ Some instruments are accessible for the measurement of anxious and phobic patients were developed which are 'The Corah's dental anxiety scale' (CDAS), 'modified dental anxiety scale' (MDAS), and 'dental fear survey' (DFS). 5,6 These instruments are the most commonly used instruments and have been found to be more reliable and valid in multiple languages. ${ }^{7,8}$ However, people with DFA most of the time tend to avoid visiting to the dentist and neglect their oral health although the treatment is necessary and this behavior worsens the situation and may lead to severe dental problems and ultimately results in a forceful visit to the dentist. Appukuttan, in her article about management of DFA claimed that dental fear is closely related to painful stimulus and increased pain perception, and as a result, these patients experience more pain than an average person which also lasts longer than normal; moreover, they also tend to exaggerate their memory of pain. This study tends to review some study of different authors who had contributed to this field earlier.

\section{Objectives}

The aim of the study was the objective of this study were as follow: to measure dental fear and dental anxiety, to evaluate the consequence and etiology of dental fear, to assess different management technique for dental fear.

\section{DISCUSSION}

The studies had found that dental fear and anxiety most often results from a traumatic past dental experience or 'conditioning via aversive treatment experience.' ${ }^{10}$ When a traumatic dental experience occur in childhood it has a long lasting effect; even after reaching adulthood it may remain. ${ }^{11}$ Another study examined how children acquire dental fear and a significant relationship between dental fear and anxiety, and the number of extractions a child had experienced and non-invasive treatment experiences resulted less dental fear. ${ }^{12}$ Some other study showed, sexual assault victims reported high dental anxiety compared to others. ${ }^{13-15}$ These findings suggests that not only traumatic dental experience but also other traumatic experiences can be a big reason behind DFA. Besides, indirect vicarious experiences can also be the cause of DFA like hearing or witnessing a negative experience of family members or friends by the child without being aware of it. ${ }^{16}$ A significant relationship found between child and parental dental fear in a systematic review and meta-analysis of 43 experimental studies about parental and child dental fear. ${ }^{17}$ Another study found fathers play a big role in transferring dental fear experience on child and mother. ${ }^{18}$ The study of Locker et al showed that $56 \%$ of the respondents suffering from DFA had a parent or sibling who also suffered from DFA. ${ }^{11}$ Media can also play a significant role in the development of DFA. Individuals with high DFA had heard or seen frightening stories about dental treatment in the media and were two and a half times frightened than other respondents. ${ }^{13}$ Personality traits play a big role behind DFA. The predominant model of personality or 5-factor model divides personality into $5 \mathrm{big}$ traits and among these neuroticisms (self-consciousness, hostility and depressive symptoms) and extraversion (warmth, excitement seeking and assertiveness) traits are related to DFA. ${ }^{19-21}$ These results suggest that highly neurotic or introverted individuals are more sufferer of DFA.

In managing the dental fear bringing change in the dental office environment is an effective way in reducing dental fear and anxiety. Besides, the staffs in a dental office also plays vital role in making a comfortable environment. They must be positive, empathetic, and caring to make the patients comfortable. A study found association between the distinctive sights, sounds, smells and sensations of the dental environment with feelings of anxiety and anticipation of pain. ${ }^{22}$ Reducing these stress-triggers can be an effective procedure for managing anxious patients. ${ }^{23}$ A study found that individuals preferred for offices adorned with posters and pictures, the waiting area supplied with ample books and magazines rather than bare walls and showed preference for a slightly cooler temperature. ${ }^{24}$ The sounds produced from the instruments in the treatment room should be muted by closing the door so that the patients waiting outside may not be frightened. ${ }^{24}$ Some studies found that smell, can influence reducing anxiety and can trigger negative emotions. Inhalation of pleasant scents has an anxiolytic effect in improving mood, but it was more efficient in managing moderate rather than severe anxiety. ${ }^{25,26}$ Several studies found that inhalation of lavender scent can pointedly reduce the levels of salivary cortisol, salivary chromogranin, and serum cortisol, increase blood flow, and decrease galvanic skin conductance and systolic blood pressure. ${ }^{27,28}$ The respondents in this study interestingly respond that a lavender scent exhibited lower state anxiety. ${ }^{27}$

This study is reliable with the results of previous studies using lavender or orange scent in dental waiting rooms. ${ }^{29,30}$ Lehrner et al in their study also insisted on not to make to anxious patients wait too long as longer waiting times give them ample time to recall all the threatening stimuli. ${ }^{29,30}$ Studies also suggested that sensory-adapted dental environment (SDE) can be helpful in management of anxiety and fear for pediatric patients. Shapiro et al adapted a "Snoezelen" dental environment for children which was comprised of dimmed lighting, soothing music, and a Velcro butterfly vest that holds the child, providing a calming, deep-pressure sensation and children with developmental disabilities have been benefitted also. ${ }^{31,32} \mathrm{~A}$ good patient-dentist relationship is very important as behavior, attitude, and communicative stance of the dentist has a crucial role in calming a patient with DFA. ${ }^{33,34}$ Besides, converse with patient, and listen to them carefully in an empathetic, calm, composed, and non-judgmental way is also efective. ${ }^{35}$ Besides, dentists must take time to 
inquire and listen about their fears and concerns (iatrosedative technique). The patients should be convinced that their words are taken seriously. ${ }^{33,34,36}$ Transparency about the treatment procedures should always be maintained regarding problem description, treatment options, and preventive procedures and patients should be encouraged to ask questions about the treatment which can help to correct misconceptions about the treatment and increase a sense of predictability and prepare the patients mentally. ${ }^{37}$ Hence, dentists must avoid false reassurances, as these can break their trust. ${ }^{9}$ A friendly, sensitive, and sympathetic approach is always well appreciated by patients. ${ }^{38}$ Thoughts of losing control over the treatment procedure is one of the main causes behind dental fear and anxiety, and that's why providing control is necessary. Tell-show-do is the widely used technique to make aware the patient about the new procedure which reduce the fear. ${ }^{39}$ Modelling is a technique used to reduce anxiety. It is observation of a dental procedure, either by viewing a video-clip where a model will demonstrate appropriate cooperative behavior during treatment procedure or through observation of an actual dental procedure. ${ }^{40}$ Before setting up a modelling program, some details must be taken into consideration; the model should be close to the age of the patient, the model should be shown entering and leaving the surgery to prove treatment has no lasting effect or pose no threat and the dentist should be portrayed to be a caring person. ${ }^{41}$ Behavioral control involves giving the patient a chance to feel that they are in control of the treatment procedure. It involves being able to signal the dentist to stop the procedure if they any type of discomfort. Anxious patients can also be given mirrors to observe the procedure, to make them feel that they are in control. ${ }^{42}$

Psychotherapeutic management is also important is managing DFA like behavior-management techniques, relaxation techniques, distraction, guided imagery, hypnotherapy, acupuncture, systematic desensitization or exposure therapy, positive reinforcement, cognitive restructuring and pharmacological management. A relaxation technique is deep breathing and progressive muscular relaxation which lowers stress and anxiety levels and helps a person to cope with the symptoms of anxiety. Multiple relaxation techniques have been proposed; Jacobsen's progressive muscular relaxation, deep breathing, functional relaxation, the rapid-relaxation technique, autogenic relaxation, and relaxation response. Progressive muscle relaxation is a systematic technique in treating people with dental anxiety. This involves tensing or tightening specific muscle groups for 5-7 seconds, followed by 20 seconds of relaxation phase with release of the tension. For example, Berggren et al. found that, in comparison to a cognitive therapy, progressive muscle relaxation had reduced dental fear and general anxiety more significantly. ${ }^{43-47}$ Deep relaxation or diaphragmatic breathing is capable to improve the mood and to reduce the levels of stress in the chest and provides more oxygen for the body per breath. It is difficult to be tense and anxious and to breathe from your abdomen at the same time. It is also believed that relaxation breathing can also be effective in reducing perceived pain. ${ }^{51}$ There are some variations can be found on relaxation breathing in different studies. ${ }^{47,52}$ Hence, it is recommended to use relaxation breathing and muscle relaxation simultaneously. Guided imagery and biofeedback can also be combined with these relaxation techniques.

Distraction is a technique of diverting the patient's attention from a perceived unpleasant procedure to any specific alternative visual or auditory stimuli for example, background music, television sets, computer games, and 3D video glasses for watching movies. ${ }^{39}$ In music distraction technique patient listens to pleasant and calming music during a long stressful procedure which can influence human brain waves, leading to deep relaxation and reduction of pain and anxiety of both children and adult. ${ }^{53,54}$ Also the use of virtual reality goggles in showing $2 \mathrm{D}$ and $3 \mathrm{D}$ vision accompanied by sound can reduce blood pressure, pulse rate and pain ratings in patients undergoing dental procedures. ${ }^{55,56}$ Guided imagery or guided affective imagery, is a mind-body intervention by which a trained practitioner helps a patient to generate mental images like pleasant, tranquil experience to achieve relaxation, thereby reducing anxiety. ${ }^{57}$ There are generally three stages to guided imagery: relaxation, visualization, and positive suggestion. ${ }^{55}$ At first patients are asked to sit quietly, slow their breathing, relax their muscles and then to picture a place of peace and relaxation. Patients are allowed to choose their own mental image or they can be guided by the dentist by using a script. The dental practitioner should be calm and relaxed while guiding the patient through the scene. Patients are instructed to imagine a scenario full of small details, along with sound, smell, and colors as an attempt to engage as many of the patient's senses (sight, sound, touch, smell) and memories as possible. This technique produces wonderful, soothing relaxation throughout the body. It can be used along with relaxation techniques. The effectiveness of guided imagery in treating distress, mood, and anxiety symptoms associated with chronic pain, social anxiety disorder, attention deficit, and cancer pain have been proven in different studies. ${ }^{58}$

Hypnotherapy is a technique of human mind involving focused attention, reduced peripheral awareness, and an enhanced capacity to respond to suggestion. It is an interactive process whereby a hypnotist attempts to influence a person's perceptions, feelings, thinking and behavior by asking them to concentrate on ideas and images in order to evoke an intended effect. ${ }^{59}$ It is quite similar to that experienced when a person is lost in their own thoughts or in a daydream, or being absorbed in a book. The technique is inexpensive, and has a very low risk of side effects but it should to be avoided in those with mental illness, personality disorders, and neurodegenerative disorders. Dentists require special training before they can practice hypnotherapy. Studies have shown that it is effective in anxiety reduction and helps people to handle stressful dental treatments. ${ }^{60,61}$ Another technique is acupuncture which is a form of 
alternative medicine where the disease is treated by inserting needles at various points on the body, known as acupuncture points. It has been found that acupuncture is effective in treating dental problems such as anxiety, temporomandibular dysfunction syndrome, pain, and Sjogren's syndrome. The use of auricular acupuncture for treating chronic and acute anxiety have shown promising results. ${ }^{62,63}$ A randomized controlled trial which compared auricular acupuncture with intranasal midazolam for managing dental anxiety found that both treatment methods were similarly effective. ${ }^{64}$ Similarly in a systematic review and meta-analysis on the effect of acupressure on anxiety, it was found that Acupuncture was effective in relieving anxiety from the anticipation of surgery or treatment. ${ }^{65}$

Systematic desensitization or exposure therapy is a technique where the patient is exposed to progressively more anxiety-provoking stimuli and taught relaxation techniques. This involves three sets of activities. At first, encourage the patients to discuss their status of fear and anxiety, in order to construct a hierarchy of feared dental situations, from the least to the most anxiety-provoking then teach the patient relaxation techniques and the final step is to gradually expose the patient to these situations in the hierarchy, from the least to the most anxietypromoting. ${ }^{66}$ In dental scenario it involves gradually exposing a fearful patient to the aspects of dentistry he/she finds frightening. Systematic desensitization has been shown to be effective in treating dental fear and anxiety. Hakeberg et al found that dentally fearful patients completing a systematic desensitization program showed greater fear reduction and an improvement in mood after receiving dental treatment compared to those patients premedicated with diazepam prior to dental treatment and the results remained consistent at 10 -year follow-up. ${ }^{66}$ Positive reinforcement is an effective technique that includes rewarding desired behaviors and thus strengthening the recurrence of those behaviors. For example, as a consequence of a particular behavior, if a dental patient receives something valuable, materially or otherwise, then we can say that the behavior has been positively reinforced. It should be kept in mind that that there is not a universal positive reinforcer; it must be one that is valued by the individual in order to strengthen the behavior. Reinforcers can be anything from a gift to smile. The social ones are most valued, such as facial expressions, tone of voice, praise and physical demonstration of affection. ${ }^{67}$ Thoughts and expectations can trigger different feelings and physiological reactions. Misconceptions and negative thoughts play a big role behind fear and anxiety. Anxious patients most often have misconceptions about dental treatment. Unlike distraction and guided imagery which aim to shift a patient's attention away from the fear-evoking situation, cognitive restructuring aims to alter and restructure the content of a person's negative cognitions. The modification of such negative cognitions helps in reducing anxiety. The technique involves identifying the misinterpretations and negative thoughts associated with dental fear, challenging the patient's misconceptions for them, and then replacing them with more realistic thoughts. Also, several studies have shown effectiveness of cognitive restructuring in dental fear and anxiety. ${ }^{68,69}$

Sedation and general anesthesia are used in pharmacological management. Pharmacological approach is well established in the management of patients with dental phobia. Pharmacological methods should be used only in situations where the patient is not able to respond and cooperate well with psychotherapeutic methods and is not willing to undergo any type of dental procedure where it is unavoidable. While dealing patients with special needs such as; mental retardation, autism, mental illness, traumatic brain injury, pharmacological management may become necessary. ${ }^{70}$ Some clinical situations can also necessitate pharmacological management. ${ }^{71}$ However, the acceptability of pharmacological approaches in the management of dental fear and anxiety is less than psychological approach among both, individuals with extreme dental fear and general public. ${ }^{72,73}$

\section{CONCLUSION}

Anxiety, stress, and pain are a universal human problem of all ages. Hence the dentistry has been always associated to anxiety and pain which is considered to be inseparable. People of different ages can suffer from DFA. And as a result, they tend to avoid dental treatment. But this narrative review had presented some way out for measuring the level of DFA and managing the DFA with several scientific technique from different study which were conducted in this field. Cooperation of both the dentists and the patients have a major role in making the dental treatment less fearful. Besides, it is required to make the people more aware about the necessity of dental treatment. If the management techniques which are mentioned above can be implemented properly, it may be possible to make the people convince and encourage for dental treatment also reduce the fear and anxiety towards it.

\section{Funding: No funding sources \\ Conflict of interest: None declared \\ Ethical approval: Not required}

\section{REFERENCES}

1. Seligman LD, Hovey JD, Chacon K, Ollendick TH. Dental anxiety: An understudied problem in youth. Clin Psychol Rev. 2017;55:25-40.

2. Moore R. The phenomenon of dental fear: Studies in clinical diagnosis, measurement and treatment (Doctoral dissertation, Department of Child Dental Health and Community Dentistry, Dental Phobia Research and Treatment Center, Royal Dental College). 1991.

3. Lautch H. Dental phobia. $\mathrm{Br} \mathrm{J}$ Psychiatry. 1971;119(549):151-8. 
4. Freeman R. Barriers to accessing dental care: patient factor. Br Dent J. 1999;187(3):141-4.

5. Newton JT, Buck DJ. Anxiety and pain measures in dentistry: a guide to their quality and application. $\mathbf{J}$ Am Dent Assoc. 2000;131(10):1449-57.

6. Buchanan H. Acquisition and measurement of dental anxiety: a summary paper. Soc Sci Dent. 2012;2:106.

7. Armfield JM. How do we measure dental fear and what are we measuring anyway? Oral health \& preventive dentistry. 2010;8(2).

8. Luyk NH, Beck FM, Weaver JM. A visual analogue scale in the assessment of dental anxiety. Anesthesia progress. 1988;35(3):121.

9. Appukuttan DP. Strategies to manage patients with dental anxiety and dental phobia: literature review. Clinical, cosmetic and investigational dentistry. 2016;8:35.

10. Locker D, Thomson WM, Poulton R. Psychological disorder, conditioning experiences, and the onset of dental anxiety in early adulthood. J Dent Res. 2001;80(6):1588-92.

11. Locker D, Liddell A, Dempster L, Shapiro D. Age of onset of dental anxiety. J Dent Res. 1999;78(3):7906.

12. Ten Berge M, Veerkamp JS, Hoogstraten J. The etiology of childhood dental fear: the role of dental and conditioning experiences. J Anxiety Disord. 2002;16(3):321-9.

13. Humphris G, King $K$. The prevalence of dental anxiety across previous distressing experiences. J Anxiety Disord. 2011;25(2):232-6.

14. Leeners B, Stiller R, Block E, Görres G, Imthurn B, Rath W. Consequences of childhood sexual abuse experiences on dental care. J Psychosomatic Res. 2007;62(5):581-8.

15. Uziel N, Bronner G, Elran E, Eli I. Sexual correlates of gagging and dental anxiety. Comm Dent Health. 2012;29(3):243.

16. Rao A. Principles and practice of pedodontics. Jaypee Digital. 2008.

17. Themessl-Huber MA, Freeman R, Humphris G, Macgillivray S, Terzi N. Empirical evidence of the relationship between parental and child dental fear: a structured review and meta-analysis. Int J Paediatric Dentistry. 2010;20(2):83-101.

18. Lara A, Crego A, Romero-Maroto MA. Emotional contagion of dental fear to children: the fathers' mediating role in parental transfer of fear. Int $\mathbf{J}$ Paediatric Dentistry. 2012;22(5):324-30.

19. Costa Jr PT, McCrae RR. Revised NEO personality inventory (NEO-PI-R) and NEO five-factor (NEOFFI) inventory professional manual. Odessa, Fl: PAR. 1992.

20. Halonen H, Salo T, Hakko H, Räsänen P. Association of dental anxiety to personality traits in a general population sample of Finnish University students. Acta Odontologica Scandinavica. 2012;70(2):96100.
21. Matthews G, Deary IJ, Whiteman MC. Personality traits. Cambridge University Press. 2003.

22. Shapiro M, Melmed RN, Sgan-Cohen HD, Eli I, Parush S. Behavioural and physiological effect of dental environment sensory adaptation on children's dental anxiety. Eur J Oral Sci. 2007;115(6):479-83.

23. Hmud R, Walsh LJ. Dental anxiety: causes, complications and management approaches. Int Dentistry SA. 2007;9(5):6-14.

24. Bare LC, Dundes L. Strategies for combating dental anxiety. J Dent Educ. 2004;68(11):1172-7.

25. McCaffrey R, Thomas DJ, Kinzelman AO. The effects of lavender and rosemary essential oils on test-taking anxiety among graduate nursing students. Holistic Bursing Practice. 2009;23(2):88-93.

26. Chen YJ, Shih Y, Chang TM, Wang MF, Lan SS, Cheng FC. Inhalation of neroli essential oil and its anxiolytic effects in animals. InProceedings of measuring behavior. 2008;256-7.

27. Kritsidima M, Newton T, Asimakopoulou K. The effects of lavender scent on dental patient anxiety levels: a cluster randomised-controlled trial. Comm Dentistry Oral Epidemiol. 2010;38(1):83-7.

28. Toda M, Morimoto K. Effect of lavender aroma on salivary endocrinological stress markers. Arch Oral Biol. 2008;53(10):964-8.

29. Lehrner J, Eckersberger C, Walla P, Pötsch G, Deecke L. Ambient odor of orange in a dental office reduces anxiety and improves mood in female patients. Physiol Behavior. 2000;71(1-2):83-6.

30. Lehrner J, Marwinski G, Lehr S, Johren P, Deecke L. Ambient odors of orange and lavender reduce anxiety and improve mood in a dental office. Physiol Behavior. 2005;86(1-2):92-5.

31. Shapiro M, Melmed RN, Sgan-Cohen HD, Parush S. Effect of sensory adaptation on anxiety of children with developmental disabilities: A new approach. Pediatric Dentistry. 2009;31(3):222-8.

32. Cermak SA, Stein Duker LI, Williams ME, Lane CJ, Dawson ME, Borreson AE, Polido JC. Feasibility of a sensory-adapted dental environment for children with autism. Am J Occup Therap. 2015;69(3):6903220020.

33. Friedman N. Iatrosedation: the treatment of fear in the dental patient. J Dent Educ. 1983;47(2):91-5.

34. Friedman N, Wood GJ. An evaluation of the iatrosedative process for treating dental fear. Compendium of Continuing Education in Dentistry (Jamesburg, NJ: 1995). 1998;19(4):434-6.

35. Marci CD, Ham J, Moran E, Orr SP. Physiologic correlates of perceived therapist empathy and socialemotional process during psychotherapy. J Nervous Ment Dis. 2007;195(2):103-11.

36. Botto RW, Donate-Bartfield E, Nihill P. Chairside techniques for reducing dental fear. Behavioral Dentistry. Oxford: Blackwell. 2006;115-25.

37. Armfield JM, Heaton LJ. Management of fear and anxiety in the dental clinic: a review. Aust Dent J. 2013;58(4):390-407. 
38. Corah NL. Dental anxiety. Assessment, reduction and increasing patient satisfaction. Dent Clin North Am. 1988;32(4):779-90.

39. McTigue DJ. Behavior management for the pediatric dental patient. Pediatric Dentistry. 2004;26(2):110.

40. Bandura A, Walters RH. Social learning theory. Prentice Hall: Englewood cliffs. 1977.

41. Farhat-McHayleh N, Harfouche A, Souaid P. Techniques for managing behaviour in pediatric dentistry: comparative study of live modelling and tell-show-do based on children's heart rates during treatment. J Canad Dent Assoc. 2009;75(4).

42. Armfield JM, Heaton LJ. Management of fear and anxiety in the dental clinic: a review. Aust Dental J. 2013;58(4):390-407.

43. Jacobson E. Progressive relaxation. 2nd edition. Chicago: University of Chicago Press. 1938.

44. Bernstein DA, Borkovec TD. Progressive relaxation training: A manual for the helping professions. Psychology. 1973.

45. Conrad A, Roth WT. Muscle relaxation therapy for anxiety disorders: it works but how? J Anxiety Disord. 2007;21(3):243-64.

46. Berggren U, Hakeberg M, Carlsson SG. Relaxation vs. cognitively oriented therapies for dental fear. J Dent Res. 2000;79(9):1645-51.

47. Weinstein P, Milgrom P, Heaton LJ. Treating Fearful Dental Patients: A Patient Management Handbook. Dental Behavioral Resources. 2009.

48. Perciavalle V, Blandini M, Fecarotta P, Buscemi A, Di Corrado D, Bertolo L, Fichera F, Coco M. The role of deep breathing on stress. Neurological Sciences. 2017;38(3):451-8.

49. Biggs QM, Kelly KS, Toney JD. The effects of deep diaphragmatic breathing and focused attention on dental anxiety in a private practice setting. J Dent Hygiene. 2003;77(2):105-13.

50. Bourne EJ. The anxiety and phobia workbook. 2nd edition. Oakland: New Harbinger. 1995.

51. Schaffer SD, Yucha CB. Relaxation \& Pain Management: The relaxation response can play a role in managing chronic and acute pain. Am J Nursing. 2004;104(8):75-82.

52. Ackley DC. Dental fear. Aren't you tired of it? Dentistry Today. 2003;22(1):96-102.

53. White JM. State of the science of music interventions: critical care and perioperative practice. Crit Care Nursing Clin N Am. 2000;12(2):219-25.

54. Moola S, Pearson A, Hagger C. Effectiveness of music interventions on dental anxiety in paediatric and adult patients: a systematic review. JBI Evidence Synthesis. 2011;9(18):588-630.

55. Hoffman HG, Garcia-Palacios A, Patterson DR, Jensen M, Furness III T, Ammons Jr WF. The effectiveness of virtual reality for dental pain control: a case study. Psychol Behavior. 2001;4(4):527-35.

56. Furman E, Jasinevicius TR, Bissada NF, Victoroff KZ, Skillicorn R, Buchner M. Virtual reality distraction for pain control during periodontal scaling and root planing procedures. J Am Dent Assoc. 2009;140(12):1508-16.

57. Complementary, Alternative, or Integrative Health: What's In a Name? US Department of Health and Human Services. Public Health Service. National Institutes of Health. NIH Publication No. D347. 2015. Available at: https://www.nccih.nih. gov/health/complementary-alternative-orintegrative-health-whats-in-a-name. Accessed on 31 January 2022.

58. Hirschman R. Physiological feedback and stress reduction. Poster presented at: Annual Meeting of Society of Behavioral Medicine. 1980.

59. British Psychological Society. The nature of hypnosis. A report prepared by a Working Party at the request of The Professional Affairs Board of The British Psychological Society. Leicester: The British Psychological Society. 2001.

60. Flammer E, Bongartz W. On the efficacy of hypnosis: A meta-analytic study. Contemporary Hypnosis. 2003;20(4):179-97.

61. Glaesmer H, Geupel H, Haak R. A controlled trial on the effect of hypnosis on dental anxiety in tooth removal patients. Patient Education and Counseling. 2015;98(9):1112-5.

62. Ernst E, Pittler MH. The effectiveness of acupuncture in treating acute dental pain: a systematic review. $\mathrm{Br}$ Dent J. 1998;184(9):443-7.

63. Rosted P. The use of acupuncture in dentistry: a review of the scientific validity of published papers. Oral diseases. 1998;4(2):100-4.

64. Karst M, Winterhalter M, Münte S, Francki B, Hondronikos A, Eckardt A, Hoy L, Buhck H, Bernateck M, Fink M. Auricular acupuncture for dental anxiety: a randomized controlled trial. Anesthesia \& Analgesia. 2007;104(2):295-300.

65. Au DW, Tsang HW, Ling PP, Leung CH, Ip PK, Cheung WM. Effects of acupressure on anxiety: a systematic review and meta-analysis. Acupuncture in Medicine. 2015;33(5):353-9.

66. Hakeberg M, Berggren U, Carlsson SG. A 10-year follow-up of patients treated for dental fear. Eur $\mathbf{J}$ Oral Sci. 1990;98(1):53-9.

67. Roberts JF, Curzon ME, Koch G, Martens LC. Behaviour management techniques in paediatric dentistry. Eur Arch Paediatric Dentistry. 2010;11(4):166-74.

68. Berggren U, Hakeberg M, Carlsson SG. Relaxation vs. cognitively oriented therapies for dental fear. J Dent Res. 2000;79(9):1645-51.

69. De Jongh AD, Muris P, Ter Horst G, Van Zuuren F, Schoenmakers N, Makkes P. One-session cognitive treatment of dental phobia: preparing dental phobics for treatment by restructuring negative cognitions. Behaviour Research and Therapy. 1995;33(8):94754.

70. Folayan MO, Faponle A, Lamikanra A. A review of the pharmacological approach to the management of dental anxiety in children. Int J Paediatric Dentistry. 2002;12(5):347-54. 
71. Newton T, Asimakopoulou K, Daly B, Scambler S, Scott S. The management of dental anxiety: time for a sense of proportion? Br Dent J. 2012;213(6):271-4.

72. Forbes MD, Boyle CA, Newton T. Acceptability of behaviour therapy for dental phobia. Comm Dentistry Oral Epidemiol. 2012;40(1):1-7.

73. Newton JT, Naidu R, Sturmey P. The acceptability of the use of sedation in the management of dental anxiety in children: views of dental students. Eur J Dent Educ. 2003;7(2):72-6.

Cite this article as: Nishi NJ, Pervin S, Shaude S. Dental fear: a narrative review. Int J Res Med Sci 2022;10:777-83. 